\title{
ADMINISTRANDO RISCO DE TAXAS DE JUROS EM INSTITUIÇÕES FINANCEIRAS
}

\author{
Silvio Aparecido de Carvalho \\ Doutor em Ciências Contábeis pela FEA/USP
}

O contexto bancário em todo o mundo tem se caracterizado pela instabilidade, provocada tanto por situações políticas quanto por situações econômicas, gerando, conseqüentemente, urna alta volatilidade nas taxas de juros, o que tem exigido dos gestores bancários o desenvolvimento e sofisticação de técnicas que permitam o adequado controle voltado minimização de riscos.

\section{1) O Contexto Econômico e suas Implicações}

No Brasil, a otimização da margem financeira ${ }^{1}$ num contexto mais amplo nunca foi muito explorada, pois os bancos têm sua rentabilidade determinada significativamente em função da inflação. Mas, à medida que economia se desenvolver e o processo inflacionário declinar, administrar a margem financeira será de vital importância, tanto no que se refere a maximização de resultados quanto à própria continuidade da entidade.

Em outras palavras, quando as taxas flutuam, em economias de baixa inflação, em função de oscilações econômicas ou por competitividade de rendimentos bancários se tornam volátiles e sensíveis, necessitando o acompanhamento e as atuações da administração se tornem mais efetivos.

Portanto, um banco em uma economia mais desenvolvida atua com uma maior sensibilidade às taxas de juros, em função de fatores endógenos ou exógenos. Endógenos são os fatores associados à composição dos ativos passivos, á qualidade e maturidade dos empréstimos e à maturidade dos fundos captados. Fatores exógenos incluem condições econômicas e o nível das taxas de juros. Um banco deve tentar gerenciar os fatores endógenos. mas ele somente pode tentar antecipar os fatores exógenos.

\section{1) O Impacto dos Fatores Exógenos}

Atendo-se à perspectiva dos bancos, o cenário econômico gera profundas implicações. A aceleração nos negócios durante a expansão econômica, de maneira conjunta com acréscimos nas taxas de juros, deve ter efeitos anormais na margem financeira. Esses efeitos se traduzem na taxa de juros, no volume e no mix das operações.

Lembramos que, em mercados competitivos, tanto as fontes de fundos como os usos desses fundos restringem a habilidade do banco em operar com a mais alta margem financeira, ou seja, com "spread" .

\footnotetext{
${ }^{1}$ Margem Financeira consiste na diferença entre as receitas de juros, geradas pelas aplicações, e as despesas de juros, geradas pelas captações. Em outras palavras. Margem Financeira é o resultado da receita financeira deduzida da despesa financeira de um determinado produto financeiro (maiores detalhes, vide CARVALHO. Silvio de. Op. cit. nota 9, e a nossa tese de doutorado)

"Spread" - financeiramente, significa uma taxa bruta que a instituição financeira cobra do tomador de empréstimos, além do seu custo de captação para obtenção de recursos. Esta taxa bruta visa cobrir as despesas em que a instituição financeira incorre para captar recursos (inclusive o risco da aplicação), e ainda proporcionar resultados para remunerar os acionistas. Ressaltamos que o "spread" usualmente utilizado pelo mercado (diferença entre as taxas de aplicação - ta e de captação- t c) mede, tão somente, o "spread" futuro, e objetivando medir o "spread" no momento da negociação (valor presente) propomos a seguinte fórmula

"Spread" $\left.=\left\{\frac{1+\mathrm{ta}}{1+\mathrm{tc}}\right)-1\right\}-\times 100$
} 
Os efeitos no volume ocorrem, simplesmente, devido à intensa demanda de crédito durante os períodos de rápido crescimento econômico, forçando para taxas mais altas e, portanto, gerando maiores níveis de ativos e passivos. Os efeitos de mix são sentidos na mudança dos "portfólios' em direção a ativos de maior rentabilidade (exemplo: empréstimos), afastando-se de ativos com baixas taxas (exemplo: títulos governamentais). O efeito das taxas de juros em situação de expansão da economia tende a melhorar a margem financeira, em função do acréscimo dos rendimentos do ativo, que podem ser reduzidos ou neutralizados pelo efeito negativo do aumento marginal das taxas nos custos dos fundos e de aumento de risco de inadimplência nos empréstimos".

A grande disparidade na sensibilidade aos juros entre os bancos e o prognóstico de que as taxas de juros possam flutuar significativa e rapidamente nos anos vindouros leva-nos a crer que os bancos necessitarão de técnicas para gerenciar a sensibilidade ás taxas de juros. Este artigo apresenta as técnicas "gap" (3) e "duration, abordadas em profundidade em minha tese de doutoramento 'Desenvolvimento de Novas Técnicas rara a Gestão Bancária no Brasil".

\section{2) O Sistema de Administração do "Gap" entre Recursos e Aplicações}

O risco de taxa de juro pode ser definido como o efeito de mudanças nas taxas de juros no valor de um único ativo, no valor do "portfólios" de ativos ou na diferença entre os valores de um portfólios" de ativos e o "portfólios" de passivos que lastreiam os ativos e, por último, obviamente, na diferença representada pelo patrimônio líquido. Essas diferenças são denominadas “gap’.

$\mathrm{Na}$ implantação de um sistema de gerenciamento do "gap", procura-se em um primeiro passo, agrupar os itens de ambos os lados do balanço, aqueles que são sensíveis às taxas de juros á curto prazo. Dessa forma, um ativo ou passivo é identificado como sensível, se o seu fluxo de caixa se altera no mesmo sentido da mudança da taxa de juros á curto prazo. O fluxo de caixa de ativos ou passivos não-sensíveis não muda dentro de um relevante período de tempo. Alguns desses ativos ou passivos não-sensíveis não têm pagamentos de juros ou custos.

\section{Figura 1}

llustração do “GAP”, em um Balanço Bancário

Ativos Passivos

\begin{tabular}{|c|c|c|}
\hline AS & S & PS \\
\hline & SNS & PNS \\
\hline ANS & NS & PL \\
\hline
\end{tabular}

3 (Maiores detalhes, vide CARVALHO. Silvio de. up.cit. nota 9. e a nossa tese de doutorado). No Brasil, nos meios bancários, a palavra "gap' tem sido traduzida como desbalanço entre ativos e passivos sensíveis à taxa de juros". 
A área S representa os ativos sensíveis sendo financiados pelos passivos sensíveis.

A área SNS indica que os ativos sensíveis estão sendo financiados pelos passivos não-sensíveis.

A área NS mostra os passivos não-sensíveis financiando os ativos nãosensíveis.

Importante lembrar que o patrimônio líquido, o ativo permanente, os depósitos à vista e o "floating" são tratados como sendo não-sensíveis".

Os ativos sensíveis são:

- $\quad$ os títulos federais

- $\quad$ os títulos de curto prazo (Depósito Interfinanceiro, etc)

- $\quad$ os financiamentos com taxas variáveis ("leastng”, etc.)

- $\quad$ empréstimos com financiamentos prefixados (prestações mensais)

Os passivos sensíveis são:

- $\quad$ CDB de curto prazo

- $\quad$ captações no mercado aberto

Os ativos não-sensíveis são:

- $\quad$ imobilizado

- $\quad$ investimento

Os passivos não-sensíveis são:

- $\quad$ patrimônio líquido

- $\quad$ depósitos à vista

- "floating"

A ilustração indica um "gap" positivo (SNS), onde ativos sensíveis excedem passivos não sensíveis. Sob situação de aumento de taxa de juros de curto prazo, o "gap" positivo irá aumentar a margem financeira. Um declínio na taxa de juros a curto prazo provocará um decréscimo na margem financeira. Por outro lado, se os ativos sensíveis forem menores que os passivos sensíveis, então teremos um "gap'negativo. Com um "gap" negativo, a margem financeira irá declinar se as taxas de juros a curto prazo subirem, e aumentar, se as taxas de juros a curto prazo caírem.

\section{1) O Modelo de "Gap" Básico"}

Este modelo foi desenvolvido no final dos anos 70 pelos bancos americanos e, para ser implementado, há necessidade de se ter basicamente quatro informações:

a) a amplitude do tempo sobre o qual a margem financeira será gerenciada. Um ano é

\footnotetext{
${ }^{4}$ TOEVES, Alden L: 1-\{ANEY, William C Measuring and Managing Interest Rate Risk: A Guide lo Asset/Liability Models used in Banks and Thrifts Morgan Stanley, outubro, 1984.
} 
geralmente escolhido como sendo o "gapping period";

b) deve-se decidir se a margem financeira esperada será preservada para o "gapping period" ou

c) procurar-se-á melhorá-la. Se o caso for de preservá-la, o "gap" básico é usado para proteção da margem financeira contra mudança nas taxas de juros; se for o caso de melhorá-la, deve-se procurar adotar uma estratégia especulativa, forçando a criação de "gap";

d) na estratégia agressiva (especulativa), precisa-se especificar a previsão de taxa de juros para

o período de "gap";

e) os valores dos ativos e passivos sensíveis às taxas de juros precisam ser determinados.

Se o administrador de risco deseja proteger a margem financeira contra mudança nas taxas de juros, então o modelo do "gap" básico recomenda que este seja igual a zero. Argumenta-se que isto causa uma mudança na taxa de juros, na medida em que influencia a receita e a despesa de juros igualmente.

Por outro lado, os bancos que desejam ser mais agressivos dentro da concepção "se nós não tivermos 'gap' não poderemos ter lucro" deverão adotar a estratégia de formar "mismatches" entre os ativos e passivos sensíveis. A direção do desejável "mismatch" dependerá da previsão da taxa de juros. Se é esperado que as taxas subam, o valor do 'gap' deverá exceder zero. Neste caso, mais ativos do que passivos irão provocar um maior nível de ganhos durante o gapping period", uma vez que esse excesso de ativos será aplicado ás novas taxas. Como resultado, a margem financeira nova irá ser maior do que aquela que seria, se as taxas não subissem.

Essas recomendações são similares, mas, no sentido contrário, se as taxas declinam e são consistentes com a seguinte fórmula:

\section{$\Delta M F=A S \times A i-P S \times A i$ \\ $=$ "Gap" $\times \mathbf{A i}$}

Onde:

$\Delta \mathbf{M F}=$ mudança esperada na margem financeira

$\Delta \mathbf{i}=$ mudança esperada na taxa de juros

Para se obter uma margem financeira maior do que a inteiramente protegida, constrói-se um "gap" positivo quando $\Delta \mathrm{i}$ é positivo e um "gap" negativo quando $\Delta \mathrm{i}$ é negativo

Uma questão permanece para ser resolvida como são os ativos e passivos automaticamente repactuados várias vezes no "gapping period" tratado no "Gap".

Um ativo ou passivo é dito sujeito a ser repactuado, quando sua taxa contratual muda ou quando existe uma entrada de caixa e esta é renovada.

Um exemplo ajuda a ilustrar os pontos acerca de risco de taxa de juros e suas múltiplas mudanças. Suponha que a meta seja proteger a margem financeira. O valor do "gap" inicialmente construído dentro do 
modelo do "gap" básico pode proteger a margem financeira somente contra a primeira mudança na taxa de juros como o tempo passa no "gapping period" e a primeira data da repactuação do ativo é atingida, os fundos devem ser reempregados para fazer o "gap" agora para o "gapping period" remanescente se tornar outra vez igual a zero. Esse procedimento posiciona o banco para ganhar a margem financeira esperada no inicio do período, sem considerar a direção e a magnitude da primeira, segunda, terceira . mudança nas taxas de juros. Nós necessitamos, então, considerar somente uma mudança de taxa por "gapping period' para ilustrar o efeito do "gap" no modelo do "gap" básico.

O gerenciamento do ativo e passivo deve direcionar para mudança de taxas seqüencialmente. Nesse modelo, não se pode operar com várias taxas ao mesmo tempo, devido à limitação de se calcular o efeito de mudança de taxa sobre o valor de "gap" de todo o período.

Evidentemente, esse modelo gera grandes distorções, na medida em que não considera que os ativos e passivos serão repactuados dentro do período de "gap"

Todas as contas envolvidas na medição do "gap" são repactuadas durante o período de análise, não importa em que período a repactuação ocorre ou quando ocorre primeiro No extremo, suponha que todos os ativos sensíveis sejam repactuados no primeiro dia e que todos os passivos o são no último dia do período. $O$ modelo do "gap" básico falsamente indicaria que a margem financeira está protegida das mudanças de taxas. Por essa razão, o modelo de "gap" básico, em função dessa equação, não pode ser confiável como medida precisa de dimensionamento de risco.

\section{2) O Modelo do "Gap" Periódico}

As mais recentes literaturas esforçam-se para resolver o problema do intraperíodo, usando cálculos de "gap" periódicos. Esse modelo de gerenciamento de ativos/passivos procura medir o "gap" em cada período e, em termos seqüenciais, dos diversos períodos que fazem parte do "gapping period".

É importante observar que chamamos de "gap" de um período a diferença entre ativos e passivos sensibilizados à variação de taxa, ou seja, o fluxo de caixa de ativos e passivos e o saído de operações que sofreram alteração de taxa naquele período.

A soma dos valores dos "gap" periódicos é igual ao "gap" medido pelo modelo básico. Para evidenciar melhor os conceitos, vamos exemplificar um banco com "gap" acumulado de $\mathrm{Cr} \$ 12 \mathrm{em}$ um ano. Esse "gap" poderia ser formado de qualquer número dentro do período de "gap". Nas Figuras 2 e 3, temos alguns padrões:

\section{FIGURA 2}






FIGURA 3

Padrōes Alternativos de "Gap" Periódico

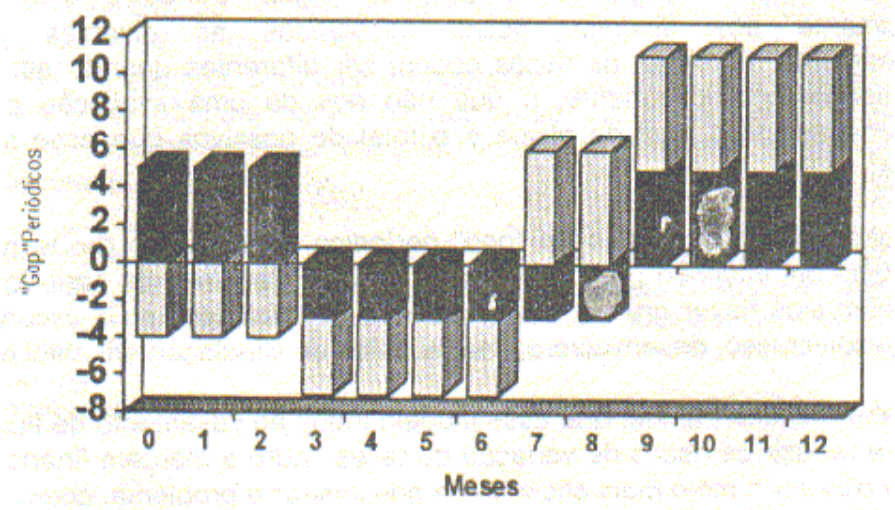

Suponhamos que um choque na taxa de juros ocorra antes que seja feita qualquer repactuação. Dentro do padrão (A) (Figura 2), haveria uma margem financeira muito diferente no final do período daquela apresentada se o padrão do "gap" fosse o (b).

O padrão o (B), colocaria mais a margem financeira sob risco do que o padrão (C) exposição da margem financeira ao risco, quando o padrão é o da Figura 3, e mais difícil de avaliar. Todavia, isso clarifica que qualquer "gap" acumulado pode ser formado de diversos "gap" periódicos e, portanto, sujeito a muitos níveis diferentes de risco.

Segundo a literatura, o modelo de "gap" periódico recomenda que a margem financeira seja protegida em todos os períodos de "gap" periódicos, tomando-os, portanto, iguais a zero. Se espera que as taxas se elevem, "gap" positivo deveria ser criado; o oposto deveria ocorrer se espera que as taxas declinem. O uso do "gap" periódico, em vez do "gap" acumulado, aumenta a probabilidade de que a margem financeira irá se comportar como esperado. 


\section{3) Vantagens e Desvantagens do Modelo de "GAP" Periódico}

A vantagem primária do modelo de "gap" periódico é o aumento na precisão para se medir o risco de taxa de juros em relação ao modelo básico. Outro ponto é a facilidade de entendimento, sendo o seu custo de desenvolvimento muito pequeno. Essas vantagens, porém, são muito poucas em comparação aos modelos de simulação de ativos e passivos.

A deficiência principal do modelo de "gap" periódico está ligada essencialmente aos diversos riscos associados às diversas contas simultaneamente. Portanto, os riscos podem ser diferentes quando as contas são analisadas individualmente, o que não nos dá uma avaliação perfeita quando analisamos o total de ativos e o total de passivos que esse modelo propõe.

Outra crítica ao modelo de "gap" periódico está no fato desse modelo também usar um intervalo grande de tempo para se definirem os períodos e de nesses intervalos haver grande probabilidade de existirem riscos escondidos. Para se resolver isso, desenvolveram-se modelos de simulação em nível diário.

Cabe ressaltar, ainda, que esse modelo induz ao casamento de fluxos de caixa para reduzir os riscos de variação de taxas sobre a margem financeira, o que pode não ser o meio mais eficiente de administrar o problema, como iremos ver nos outros métodos apresentados a seguir.

\section{4) Aplicação do “GAP” Periódico}

Como já foi dito anteriormente, a principal utilização do modelo de "gap" está na medição da sensibilidade de ativos e passivos financeiros em relação a flutuações na taxa de juros. Para tornar a quantificação desses efeitos operacionalmente mais simples e precisa, recorremos ao conceito de saldo médio em valor presente ${ }^{5}$ (5) para quantificar a massa de ativos e passivos distribuída no tempo.

Partindo-se de uma composição inicial de ativos e passivos, projetamos os saldo médio valor presente dessas operações, com base no fluxo de caixa e nas respectivas taxas, até o horizonte escolhido para a análise de sensibilidade. Dessa forma, obtemos a diferença entre os saldos médios de ativos e passivos para cada mês ("gap" período mensal) do período estudado.

\footnotetext{
${ }^{5}$ Saldo Médio em Valor Presente - é o somatório dos valores presentes diários divididos pelo número de dias do período. Tal inferência deve-se à conclusão de que a receita ou despesa do período é função direta do valor presente imediatamente anterior e que, portanto, o somatório da receita ou despesa do período é resultante do somatório dos valores presentes defasados de um período e aplicados a uma determinada taxa.
}

A fórmula que espelha o Saldo Médio em Valor Presente (SMVP) configura-se como segue:

$\mathrm{n}-1$

So $+\Sigma \quad \mathrm{S}_{\mathrm{t}}$

$\mathrm{t}=1$

SMVP $=$

n 
É importante ressaltar que o cálculo do "gap" pela diferença de saldos médios entre ativos e passivos, embora seja aparentemente diferente do procedimento descrito anteriormente, onde são utilizados fluxos de caixa, na prática conduzem aos mesmos resultados. Quando observamos, por exemplo, que num determinado período futuro o saldo projetado do ativo é maior do que o do passivo, na verdade constatamos que naquele período deverá ocorrer o resgate de captações e novas operações deverão ser feitas, a novas taxas de juros, para substituí-las.

Uma vantagem da utilização de saldos médios e a redução, no problema mencionado anteriormente, da existência de riscos escondidos, quando são considerados os fluxos de caixa em períodos muito grandes.

Ao contrário da convenção utilizada, quando calculamos o "gap" pelo fluxo de caixa, a diferença entre o saldo médio de ativos e de passivos representa, se positiva, o volume de operações passivas que deverão ter taxas renovadas no "gapping period" e vice-versa. Assim sendo, a fórmula para análise de sensibilidade da margem financeira passaria a ser escrita da seguinte forma:

\section{$\Delta \mathrm{MF}=\mathrm{SMP} \times \mathrm{n} \times \Delta \mathrm{i}-\mathrm{SMA} \times \mathrm{n} \times \Delta \mathrm{i}$ $=-$ " GAP" $\times \mathrm{n} \times \Delta \mathrm{i}$}

Onde:

$\Delta \mathrm{MF}=$ mudança esperada na margem financeira

$\mathrm{n}=$ número de dias do "gapping period" (mês)

$\Delta \mathrm{i}=$ mudança esperada na taxa exponencial diária ${ }^{6}$

SMA, SMP = saldos médios valor presente de ativos e passivos

Para um "gap" positivo, ou seja, saldo remanescentes de ativos maior do que o de passivos, um aumento de taxas implica redução na dos ativos "antigos" (existente na composição inicial) deverá ser lastreada por recursos novos captados no futuro e, portanto, sujeita às novas taxas de mercado. Nesse caso, taxas mais altas significam aumento no custo dos passivos utilizados e, conseqüentemente, redução na margem financeira.

\section{Exemplo:}

\footnotetext{
${ }^{6}$ sendo $\mathrm{St}=\mathrm{St}-1(1+\mathrm{i})+\mathrm{F}-\mathrm{L}$

onde: So $=$ Saldo inicial

St $=$ Saldo no momento $t$

$\mathrm{i}$ = Taxa de Juros da Operação

$\mathrm{n}=$ Número de Dias do Mês

$\mathrm{F}=$ Novos Financiamentos ou Novas Captações no Período

$\mathrm{L}=$ Liquidações de Financiamentos ou Resgates de Captações (valor de fluxo de caixa) $\mathrm{t}=1,2,3 \ldots . \mathrm{n}$

(Maiores detalhes, vide CARVALHO, Silvio de, op.cit. nota 9, e a nossa tese de doutorado).

De acordo com o método de cálculo do saldo médio valor presente, o resultado de uma operação financeira num determinado período é:

$\mathrm{R}=$ SMVP $\times \mathrm{n} \times \mathrm{td}$

Onde:

SMVP: saldo médio valor presente no período

$\mathrm{n}$ = número de dias do período

$\mathrm{td}=$ taxa exponencial diária da operação
} 
Para avaliação dos diferentes métodos de análise de sensibilidade da margem financeira em relação à variação na taxa de juros, utilizaremos o seguinte exemplo:

\section{Aplicação:}

Valor: Cr\$1.000,00

Prazo: 12 meses

Pagamentos: 12 parcelas iguais

Taxa: $3,0 \%$ a.m.

\section{Captação:}

Valor: Cr\$1.000,00

Prazo: 12 meses

Pagamentos: 1 única no final

Taxa: $1,5 \%$ a.m.

Cabe frisar que os exemplos foram calculados utilizando como base mensal 30 dias.

As operações do nosso exemplo podem sofrer correção monetária por algum índice, sem que esse fato prejudique nossa análise, que é vista sempre na moeda da data em que é realizada.

Na prática, porém, devemos tomar cuidado para não introduzir o efeito do risco de descasamento de moedas na análise, ou seja, devemos analisar grupos de operações com o mesmo indexador.

Vistas do instante inicial, as operações acima, projetadas pelo prazo de vencimento, apresentam os seguintes valores: 


\begin{tabular}{|c|c|c|c|c|c|c|}
\hline \multirow[b]{3}{*}{ Meses } & \multicolumn{6}{|c|}{ Operações Originais } \\
\hline & \multicolumn{3}{|l|}{ Aplicação } & \multicolumn{3}{|l|}{ Captação } \\
\hline & $\begin{array}{l}\text { Fluxo de } \\
\text { Caixa }\end{array}$ & \begin{tabular}{|lr}
$\begin{array}{lr}\text { Saldo } & \text { Final } \\
\text { (Antes r do } & \text { dagamento } \\
\text { Pa Prestação) }\end{array}$ \\
\end{tabular} & $\begin{array}{l}\text { Saldo Médio } \\
\text { Valor } \\
\text { Presente }\end{array}$ & $\begin{array}{l}\text { Fluxo de } \\
\text { Caixa }\end{array}$ & Saldo Final & $\begin{array}{l}\text { Saldo Médic } \\
\text { Valor } \\
\text { Presente }\end{array}$ \\
\hline 1 & 100,46 & $1.030,00$ & $1.014,43$ & - & $1.105,00$ & $1.007,23$ \\
\hline 2 & 100,46 & 957,42 & 942,95 & - & $1.030,23$ & $1.022,34$ \\
\hline 3 & 100,46 & 882,67 & 869,32 & - & $1.045,68$ & $1.037,67$ \\
\hline 4 & 100,46 & 805,68 & 793,49 & - & $1.061,36$ & $1.053,24$ \\
\hline 5 & 100,46 & 726,37 & 715,39 & - & $1.077,28$ & $1.069,04$ \\
\hline 6 & 100,46 & 644,68 & 634,94 & - & $1.093,44$ & $1.085,07$ \\
\hline 7 & 100,46 & 560,55 & 552,07 & - & $1.109,84$ & $1.101,35$ \\
\hline 8 & 100,46 & 473,89 & 466,72 & - & $1.126,49$ & $1.117,87$ \\
\hline 9 & 100,46 & 384,63 & 378,81 & - & $1.195,62$ & $1.134,64$ \\
\hline 10 & 100,46 & 292,69 & 288,27 & - & $1.160,54$ & $1.151,68$ \\
\hline 11 & 100,46 & 198,00 & 195,00 & - & $1.177,95$ & $1.168,93$ \\
\hline 12 & 100,46 & 100,46 & 98,94 & $(1.195,62)$ & $1.195,62$ & $1.186,47$ \\
\hline TOTAL & $1.205,55$ & - & - & $(1.195,62)$ & - & - \\
\hline
\end{tabular}

O " gap" entre os saldos das operações cresce com o tempo, colocando em risco a margem financeira esperada para o período, caso haja variações das taxas de juros, como demonstramos na Figura 4:

Figura 4

“Gap" em Saldo Médio Valor Presente 
Se a taxa de juros cair $0,5 \%$ a partir do $1^{\circ}$. Mês, podemos estimar o impacto na margem financeira, a partir do método de análise do "gap", aplicando a fórmula abaixo:

$$
\Delta \mathrm{MF} \text { mensal }=-\mathrm{GAP} \times 30 \times\left[\left(1+0,005^{1 / 30}-1\right)\right]
$$

Quadro 2

Operações Originais

(Em CR\$)

\begin{tabular}{|c|c|c|c|c|}
\hline \multirow[b]{2}{*}{ Meses } & Aplicação & Captação & & \multirow{2}{*}{ Variação na Margem Financeira } \\
\hline & Saldo Médio Valor Presente & Saldo Médio Valor Presente (b) & "GAP" (a-b) & \\
\hline 1 & $1,014,43$ & $1.007,23$ & & \\
\hline 2 & 942,95 & $1.022,34$ & 7,19 & 0,04 \\
\hline 3 & 869,32 & $1.037,67$ & $-79,39$ & $-0,39$ \\
\hline 4 & 793,49 & $1.053,24$ & $-168,35$ & $-0,82$ \\
\hline 5 & 715,39 & $1.069,04$ & $-259,75$ & $-1,26$ \\
\hline 6 & 634,94 & $1.085,07$ & $-353,65$ & $-1,72$ \\
\hline 7 & 552,07 & $1.101,35$ & $-450,14$ & $-2,19$ \\
\hline 8 & 466,72 & $1.117,87$ & $-549,28$ & $-2,67$ \\
\hline 9 & 378,81 & $1.134,64$ & $-651,15$ & $-3,17$ \\
\hline 10 & 288,27 & $1.151,66$ & $-755,82$ & $-3,68$ \\
\hline 11 & 195 & $1.168,93$ & $-863,39$ & $-4,20$ \\
\hline 12 & 98,94 & $1.186,47$ & $-973,93$ & $-4,74$ \\
\hline al & ---- & & $-1087,52$ & $-5,29$ \\
\hline & & Total & ---- & ---- \\
\hline
\end{tabular}

O Quadro 2 mostra uma redução na margem financeira de CR\$ $(30,10)$ em relação à situação de taxas anterior.

O resultado reflete o fato de que, na situação anterior, as parcelas da aplicação recebidas nos meses de 1 a 12 iriam ser aplicadas a 3.0\% a.m., enquanto na nova situação, com a queda das taxas em $05 \%$, estas serão aplicadas à taxa de $2,5 \%$ a.m.. O custo da captação, por outro lado, não é beneficiado pela queda de taxas, porque a operação só será renovada após 12 meses, mantendo o custo fixo por todo esse período.

Para verificarmos a acurácia da estimativa, mostramos, no Quadro 3, o valor presente dos fluxos de caixa da aplicação e da captação pelas novas taxas de juros de mercado. Por meio desse procedimento, calculamos com exatidão qual seria o ajuste de resultado que obteríamos caso as operações fossem contabilizadas a valor de mercado, de acordo com as novas taxas de juros. 
Quadro 3

\begin{tabular}{|c|c|c|}
\hline Meses & $\begin{array}{c}\text { Valor Presente do } \\
\text { Fluxo de Caixa } \\
\text { Aplicação }\end{array}$ & $\begin{array}{c}\text { Valor Presente do } \\
\text { Fluxo de Caixa } \\
\text { Captação }\end{array}$ \\
\hline 1 & 98,01 & - \\
\hline 2 & 95,62 & - \\
\hline 3 & 93,29 & - \\
\hline 4 & 91,01 & - \\
\hline 5 & 88,79 & - \\
\hline 6 & 86,63 & - \\
\hline 7 & 84,52 & - \\
\hline 8 & 82,45 & - \\
\hline 9 & 80,44 & - \\
\hline 10 & 78,48 & - \\
\hline 11 & 76,57 & - \\
\hline 12 & 74,70 & $(1.061,05)$ \\
\hline Total & $1.030,52$ & $(1.061,05)$ \\
\hline
\end{tabular}

\section{3) "Duration"}

\section{1) 0 Conceito de "Duration",}

Quando a análise de "duration" foi introduzida na indústria bancária, os proponentes dessa técnica anunciavam que ela responderia a todos os problemas de gerenciamento de ativos e passivos. Contudo, muitos banqueiros evitavam essa técnica, porque havia pouca discussão acerca de sua aplicação prática. Todas as discussões em torno do assunto eram teóricas, centrando-se na complexa formulação matemática.

Muito também do ceticismo acerca da análise de "duration" estava relacionado ao fato de que ela se concentrava no valor de mercado da operação, em vez de se concetrar no valor registrado na contabilidade.

Hoje, entretanto, como o mercado continua a sofisticar os mecanismos de operações, tonando o trabalho de gerenciamento de ativos e passivos mais difícil, os banqueiros estão reexaminando a análise de "duration". De outro lado, os analistas da indústria bancária estão começando a concentrar seu enfoque mais no valor de mercado.

Olham-na pela visão de como ela pode ser útil para ajuda-lo a resolver seus problemas, sem se preocuparem com a complexidade matemática existente por trás.

Muito disso se deve à série de "softwares" desenvolvidos que resolvem os problemas matemáticos. A tarefa do gestor de ativos/passivos é entender o conceito de "duration", as vantagens e desvantagens dessa técnica e como a análise de "duration" pode ajustar a estratégia de gerenciamento de ativos/passivos.

${ }^{7}$ WYDERKO, Jr., Leonard W. - Duration Analysis Revisited - Bank Administration, volume LXIV, número 10, outubro, 1988, pp 18-24

Caderno de Estudos nº10, São Paulo, FIPECAFI, Maio/1994 
A análise de "duration" pode ser definida de inúmeras formas. A definição mais comum é: "uma estimativa do prazo médio ponderado de um "portifolio".

\section{2) Taxa de Juros e Preços de "Bonds"}

Todas as pessoas ligadas ao setor bancário sabem que a taxa de juros e os preços dos "bonds" movem-se em sentido inverso, ou seja, quando as taxas de juros sobem, os preços dos "bonds" caem e viceversa. Este conceito é o ponto de início da análise de "duration".

Fredereck Macaulay ${ }^{8}$, a quem é atribuída a invenção da análise de "duration", observou que mudanças nas taxas de juros causavam mudanças nos preços dos "bonds", mas não de maneira diretamente proporcional ao seu prazo de emissão. Tentando explicar esse fenômeno, ele descobriu que o prazo do título era apenas responsável parcialmente por aquele efeito. Se o banqueiro for examinar os títulos unicamente em termos de seu prazo de vencimento ele irá ignorar o "timing" e os valores de qualquer fluxo de caixa intermediário, assim como os reinvestimentos dos rendimentos em seus fluxos de caixa. Conseqüentemente, o prazo de vencimento da operação é uma medida inadequada em relação a sua maturidade.

Macaulay desenvolveu uma fórmula que explica a relação entre os preços dos "bonds" e a taxa de juros de uma forma linear e chamou essa medida de "duration".

A análise de "duration" uso o valor presente dos fluxos de caixa intermediário, junto com o fluxo de caixa dos rendimentos, para calcular o prazo médio ponderado da operação ou "portifolio" . Uma vez calculada a "duration" da operação ou do "portifolio" , o analista pode determinar a mudança no valor de mercado, dada uma mudança na taxa de juros. Por exemplo, se um financiamento habitacional de 30 anos tem uma "duration de 10 anos, então o valor de mercado do financiamento habitacional irá reagir de acordo com a taxa de juros da mesma maneira que um "zero coupon bond" de 10 anos.

\section{3) Como calcular a "Duration"}

Para calcular a "duration", deve-se dispor de certos dados, inclusive premissas econômicas, dos fluxos de caixa da operação e da taxa de juros a ser utilizada para o cálculo do valor presente dos fluxos de caixa. Na análise da "duration", o valor de mercado é assumido como sendo o valor presente dos fluxos de caixa da operação. Dispondo desses dados, a análise de "duration" é relativamente simples, mas na prática pode ser bastante difícil, em função da qualidade dos dados.

Inicialmente, desenvolveremos uma expressão para uma mudança no valor de um ativo que consiste de um único pagamento, dada uma mudança na taxa de juros. Em seguida, desenvolveremos uma expressão análoga para complexos multipagamentos de ativos e, finalmente, uma para o patrimônio líquido.

Vamos supor que V1 seja o valor de um ativo financeiro com um único pagamento de $\mathrm{C}$ para ser recebido em $n$ anos. Assumimos, para simplificar, que a taxa de juros $\mathrm{R}$ é a mesma no vencimento. Então, aplicaremos cálculo diferencial para calcular o impacto em V1, devido a uma mudança de R;

\footnotetext{
${ }^{8}$ MACAULAY, Frederick R. - The Movements of Interest Rates, Bond Yields and Stock Prices in the United States Since 1856 - Nacional Bureau of Economic Research, New York, 1938.
} 
a) $\mathrm{V}_{1}=\mathrm{C}$

$$
\overline{(1+R)^{n}}
$$

b)

$d V_{1}=-n C$<smiles>[R][Ba][Ba]</smiles>

Quando ambos os lados de (B) são divididos por V1 (equação a).

c)

$d V_{1}=-n d R$

$$
\overline{V_{1}} \quad \overline{1+R}
$$

Por estarmos utilizando o cálculo diferencial, isso só se aplica em pequenas mudanças em $\mathrm{R}$. Entretanto, podemos dar uma razoável aproximação quando as mudanças em $R$ são mais finitas:

d)

$$
\begin{aligned}
& \Delta \mathrm{V}_{1}=-\mathrm{n} \frac{\Delta \mathrm{R}}{\mathrm{V}_{1}} \quad \frac{}{1+\mathrm{R}}
\end{aligned}
$$

As expressões $C$ e $D$ mostram que há uma relação aproximadamente linear entre as mudnaças de percentagem em $V_{1} \quad(\underline{d V 1}$ ou $\underline{\Delta V 1})$ e $R$.

$$
\mathrm{V}_{1} \quad \mathrm{~V}_{1}
$$

Suponhamos que $\mathrm{R}$ inicialmente era $10 \%$ e que $\Delta \mathrm{R}$ era $1 \%$. Adicionalmente, assume-se que há 2 (dois) únicos pagamentos desses ativos, um com a maturidade de 1 ano e outro com maturidade de 5 anos.

Substituindo em d, temos:

$\underline{\Delta V 1}=-1 \underline{(0,01)}=-0,91 \%$ por um ativo de um ano.

$\mathrm{V}_{1} \quad 1,10$

e,

$\underline{\Delta V 1}=-5 \underline{(0,01)}=-4,55 \%$ por um ativo de 5 anos.

$\mathrm{V}_{1} \quad 1,10$ 
O significado desse resultado está no fato de que o preço do ativo de 5 anos é 5 vezes mais volátil do que o de um ano. Na realidade, $n$ é um índice de risco da taxa de juros.

O índice n é, também, a "duration" de um único pagamento.

\section{4) Ativos com Multipagamentos}

Maturidade e "duration" são iguais somente para pagamentos únicos. "Duration" pode ser descrito também como um índice para multipagamentos.

Vamos supor Vm como sendo o valor de um ativo de maturidade $\mathrm{n}$ que gera uma série de fluxo de caixa $\mathrm{mCt}$, logo:

e)

$$
\begin{aligned}
& \mathrm{V}_{\mathrm{m}}=\underline{\mathrm{C}}_{1}+\quad \underline{\mathrm{C}}_{2}+\quad \underline{\mathrm{C}}_{3}+. . . .+\underline{\mathrm{C}}_{\mathrm{n}} \\
& (1+R) \quad(1+R)^{2} \quad(1+R)^{3} \quad(1+R)^{n}
\end{aligned}
$$

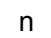

O diferencial será:

\section{f)}

$d V_{m}=-\left[\underline{C}_{1}+\underline{2 x C_{2}}+. n+\underline{C}_{n}\right] \underline{d R}$

$(1+R)^{2} \quad(1+R)^{3} \quad(1+R)^{n+1}$

Agora, dividiremos (f) por $\mathrm{V}_{\mathrm{m}}$ (equação (e)) para obter:

g)

$\underline{\mathrm{dV}}_{\mathrm{m}}=\underline{\mathrm{C}}_{1}+\underline{\mathrm{C}}_{2}+\underline{\mathrm{C}}_{3}+. . .+\underline{\mathrm{C}}_{\mathrm{n}}$

$(1+R) \quad(1+R)^{2} \quad(1+R)^{3} \quad(1+R)^{n}$

$\mathrm{V}_{\mathrm{m}}$

Que pode ser escrito como segue:

h)

Em (h), o termo entre colchetes é "duration", portanto; pode ser escrita como: 
i)

$\underline{\mathrm{d} \mathrm{V}_{\mathrm{m}}}=-\mathrm{D} \underline{\mathrm{dR}}$

$V_{m} \quad 1+R$

Uma aproximação para mudanças finitas em R é:

$$
\begin{aligned}
& \underline{\Delta v_{m}}=-D \underline{\Delta R} \\
& \mathrm{~V}_{\mathrm{m}} \quad 1+\mathrm{R}
\end{aligned}
$$

Nota-se que a forma (j) é idêntica à (d), que era utilizada para se calcular "duration" de um único pagamento. Dessa forma, "duration" é simplesmente um índice de risco da taxa de juros que capta um fluxo de caixa padrão de multipagamentos. $O$ valor (t) no numerador em (h) significa que "duration" é o médio ponderado do valor presente de uma série de fluxo de caixa. Nesse papel, como um índice de risco da taxa de juros, "duration" de um ativo com multipagamentos (d) é análogo à maturidade de um ativo com um único pagamento $(n)$.

\section{Exemplo:}

Vamos calcular o impacto da queda de $0,5 \%$ ao mês das taxas no mesmo exemplo utilizado no método do "gap", porém, agora empregando o método da "duration".

O quadro 4 mostra o fluxo de caixa ponderado pelo valor presente das operações de aplicação e de captação.

\section{Quadro 4}

\begin{tabular}{|l|l|l|l|l|}
\hline \multicolumn{1}{|c|}{$\begin{array}{c}\text { Meses } \\
\text { (a) }\end{array}$} & $\begin{array}{c}\text { Valor Presente } \\
\text { do Fluxo de } \\
\text { Caixa Aplicação } \\
(\mathrm{b})\end{array}$ & $\begin{array}{c}\text { Fluxo } \\
\text { Ponderado } \\
\text { Aplicação } \\
(\mathrm{a} \text { x b) }\end{array}$ & $\begin{array}{c}\text { Valor Presente do } \\
\text { Fluxo de Caixa } \\
\text { Captação } \\
(\mathrm{c})\end{array}$ & $\begin{array}{c}\text { Fluxo } \\
\text { Ponderado } \\
\text { Captação } \\
(\mathrm{a} \text { x c) }\end{array}$ \\
\hline 1 & 97,54 & 97,54 & - & - \\
\hline 2 & 94,70 & 189,39 & - & - \\
\hline 3 & 91,94 & 275,81 & - & - \\
\hline 4 & 89,26 & 357,04 & - & - \\
\hline 5 & 86,66 & 433,30 & - & - \\
\hline 6 & 84,14 & 504,81 & - & - \\
\hline 7 & 81,68 & 571,79 & - & - \\
\hline 8 & 79,31 & 634,45 & - & - \\
\hline 9 & 77,00 & 692,96 & - & - \\
\hline 10 & 74,75 & 747,53 & - & - \\
\hline 11 & 72,58 & 798,34 & - & $(12.000,00)$ \\
\hline 12 & 70,46 & 845,55 & $(1.000,00)$ & $(12.000,00)$ \\
\hline Total & $1.000,00$ & $6.148,50$ & $(1.000,00)$ & \\
\hline
\end{tabular}

Caderno de Estudos nº10, São Paulo, FIPECAFI, Maio/1994 
A "duration", então seria:

Aplicação: $(\underline{6.148,50})=6,15$ meses

$1.000,00$

Captação: $(\underline{12.000,00})=12$ meses

$1.000,00$

Calculamos então a volatilidade $\left(\underline{\Delta \mathrm{V}_{\mathrm{m}}} / \underline{\Delta \mathrm{V}_{\mathrm{m}}}\right)$ do valor das operações em função da variação na taxa de juros:

Aplicação: $\frac{\Delta V_{m}}{V_{m}}=-6,15 \frac{(-0,005}{1,030}=2,99 \%$
Captação: $\left.\frac{\Delta V_{m}}{V_{m}}=-12,00 \frac{(-0,005}{1,015}\right)=5,91 \%$

O quadro 5 apresenta uma síntese dos resultados:

\section{Quadro 5}

\begin{tabular}{|l|l|l|l|}
\hline & Aplicação & Captação & Margem Financeira \\
\hline "Duration" & 6,15 meses & 12,00 meses & \\
\hline Volatilidade (a) & $2,99 \%$ & $5,91 \%$ & \\
\hline $\begin{array}{l}\text { Valor Atual da Operação } \\
\text { Antes da Mudança de Taxa } \\
\text { (b) }\end{array}$ & CR\$ 1.000,00 & CR $\$(1.000,00)$ & \\
\hline Oscilação Resultado (a x b) & CR\$ 29,85 & CR\$ $(59,11)$ & CR\$ $(29,27)$ \\
\hline
\end{tabular}

O fato de a operação de captação apresentar maior "duration" implica maior volatilidade de seu valor de mercado, com respeito a oscilações nas taxas de juros, quando comparada com a aplicação. Desta forma, ao refletimos a variação dos valores de mercado na margem financeira, o efeito provocado pela queda na taxa de juros geram maior crescimento no valor da operação passiva do que no da ativa e, conseqüentemente, o ajuste na margem financeira terá mais despesa do que receita.

Como podemos observar, o impacto negativo na margem de $\operatorname{CR} \$(29,27)$ calculado pelo método da "duration" também se aproxima do valor obtido pelo cálculo exato $\mathrm{CR} \$(30,53)$. 


\section{5) Prazo Médio}

Uma outra forma de se aplicar o conceito de "duration" está na utilização do prazo médio". Este é definido como sendo o prazo da operação equivalente de mesma taxa e com o único fluxo de caixa futuro, a qual produz a mesma receita financeira da operação em estudo.

O prazo médio é expresso pela seguinte fórmula:

Onde:

$\mathrm{p}=$ prazo médio

$\mathrm{Ct}=$ fluxo de caixa no período $\mathrm{t}$

$\mathrm{R}=$ taxa de juros

$\mathrm{N}=$ número de períodos

Na verdade, o prazo médio depende de três variáveis: a taxa de juros, o valor presente da operação e a soma dos fluxos de caixa. Como, para sua obtenção não necessitamos dos valores presentes de cada parcela isoladamente, seu cálculo é muito mais simples do que o da "duration", principalmente para fluxos de caixa mais complexos.

Da mesma forma que para a "duration", o prazo médio pode ser empregado para estimar a variação no valor de um ativo resultante de pequenas variações na taxa de juros.

Para pequenas variações (...) em $\mathrm{R}$, podemos assumir que:

[

Podemos escrever a igualdade da seguinte forma:

$P \log (1+R)+\log \sum_{t=1}^{n} \frac{C^{t}}{(1+R)^{t}}$

Simplificando,

Como

é o valor presente $(\mathrm{Vm})$ dos fluxos de caixa futuros pela taxa $\mathrm{R}$; se chamarmos de $\mathrm{Vm}+$ Vm o valor presente pela nova taxa $R+\ldots R$, teremos:

\footnotetext{
${ }^{9}$ CARVALHO, Silvio A. De - Uma Contribuição á Avaliação do "Spread" e a sua Integração ao Processo de Planejamento Econômico-Financiero das Sociedades de Crédito, Financiamento e Investimento. Dissertação de Mestrado apresentada à Faculdade de Economia e Administração da Universidade de São Paulo, 1982, página 45.
} 
Chamando $S=(\underline{1+R+\Delta R})$ de "spread" financeiro entre as taxas antes e depois da variação, temos: $1+\mathrm{R}$

Cabe porém, ressaltar que a estimativa de variação do valor de ativos financeiros utiliza tanto o conceito de "duration", quanto o prazo médio. Trata-se de uma aproximação que só é válida para pequenas variações de taxa.

Na verdade, a "duration" e o prazo médio variam em função da taxa, e o cálculo exato do efeito de variações na taxa de juros sobre o valor de um ativo exigiria que esses parâmetros fossem recalculados, tirando todas as vantagens desse tipo de procedimento que estão ligadas principalmente à simplificação de cálculo.

Finalmente, a estimativa dio valor de um ativo pelo prazo médio, por ser exponencial como o cálculo exato do valor presente, é mais precisa do que a calculada pela "duration" (linear) para variações pequenas de taxa. Mas pode se tornar menos precisa à medida de que procuramos utilizar o método para oscilações maiores na taxa de juros.

Exemplo:

Aqui também utilizamos as mesmas operações do exemplo do método de "gap" para calcular o impacto na margem financeira da queda de $0,5 \%$ ao mês nas taxas de juros, através do método do prazo médio.

O prazo médio seria:

Aplicação: $\underline{\log 1.205,52-\log 1.000,00}=16,32$ meses

$\log (1+0,30)$

Captação: $\underline{\log 1.195,62-\log 1.000,00}=12,00$ meses

$\log (1+0,15)$

E a volatilidade : $\left(\Delta \underline{\mathrm{V}}_{\underline{\mathrm{m}}} / \mathrm{V}_{\mathrm{m}}\right)$

Aplicação: : $\quad \Delta \underline{V}_{\underline{m}}=(\underline{1+0,025})^{-6,32}-1=3,13 \%$

$\mathrm{V}_{\mathrm{m}} \quad 1+0,030$

Captação: $\quad \Delta \underline{\mathrm{V}}_{\underline{m}}=(\underline{1+0,010})^{-12}-1=6,11 \%$ 


$$
\mathrm{V}_{\mathrm{m}} \quad 1+0,015
$$

O Quadro 6 apresenta uma síntese dos resultados:

\section{Quadro 6}

\begin{tabular}{|l|l|l|l|}
\hline & Aplicação & Captação & Margem Financeira \\
\hline Prazo Médio & 6,32 meses & 12,00 meses & \\
\hline Volatilidade (a) & $3,13 \%$ & $6,11 \%$ & \\
\hline $\begin{array}{l}\text { Valor Atual da Operação } \\
\text { Antes da Mudança de Taxa } \\
\text { (b) }\end{array}$ & CR\$ 1.000,00 & CR\$ $(1.000,00)$ & \\
\hline Oscilação Resultado $(a \times$ b) & CR\$ 31,25 & CR\$ $(61,05)$ & CR\$ $(29,80)$ \\
\hline
\end{tabular}

A explicação do impacto negativo de $\operatorname{CR} \$(29,80)$ na margem financeira é análoga àquela do exemplo do método da "duration". Esse resultado, porém, se aproxima mais do resultado exato de CR $\$$ $(30,53)$.

\section{6) Vantagens e Desvantagens da "Duration" e do Prazo Médio}

Uma questão, quando da análise de "duration" e do prazo médio, está ligada à taxa adequada a ser utilizada para descontar os fluxos de caixa.

A taxa deveria ser uma reflexão realista da taxa de oportunidade da instituição. Na verdade, o banqueiro deverá achar útil calcular a "duration" testando várias taxas, comparando os resultados e sugerindo estratégias sob cada cenário.

Os problemas enfrentados, ao se executar a análise de "duration", não são únicos. Entretanto, desde que o enfoque são os fluxos intermediários de caixa, o rendimento reinvestido e o valor de mercado, isso força o analista a confrontar questões que podem ser evitadas em outras técnicas. Se classificássemos uma hipoteca de 30 anos em um conjunto de 10 anos, poderia ser bom para a análise do "gap", mas o fato de se desprezar a questão de pagamentos antecipados e reinvestimento dos rendimentos torna a análise frágiol $A$ análise de "duration" esforça-se para solucionar esta questão.

\section{7) Contabilidade e o Valor de Mercado}

Os administradores de instituições financeiras entendem, instintivamente, que o valor de um banco, indicado pelos valores registrados de ativos e passivos na contabilidade, não reflete o seu verdadeiro valor econômico.

A mensuração contábil de muitos itens patrimoniais de instituições financeiras reflete contratos 
nominais que foram efetuados em uma determinada conjuntura de taxas; e tal conjunturapode ter-se modificado durante a maturidade do contrato, resultando em valor nominal distinto do valor econômico do item patrimonial. Adiciona-se, ainda, as oscilações bruscas de taxas, o valor nominal (contábil) será tão somente uma referência ao gestor de ativos e passivos.

De maneira diversa da que ocorre com o valor contábil, os valores de mercado refletem as taxas de juros do cenário financeiro do momento da análise, pois a utilização de fluxos de caisa descontados pela taxa de juro efetiva do mercado financeiro infere um valor de negociação potencial para os ativos e passivos, consubstanciando-se em uma potencial cotação de mercado para os itens patrimoniais. O valor de mercado é correlato a valores de realização, de venda de ativo, de compra de passivo. Portanto, uma análise que vislumbre o valor de mercado e a sua relação com a oscilação da taxa de juros possibilita uma gestão de ativos e de passivos mais próxima da realidade de mercado em que se insere o banco.

Nesse contexto, é importante entender a relevância da "duration" dentro da amplitude de gerenciamento de ativos e passivos. No gerenciamento de ativos e passivos, "duration" é aplicada para medir, exatamente, a exposição do banco às mudanças nas taxas de juros, possibilitando mensurar o impacto da oscilação no valor de mercado dos itens patrimoniais.

\section{8) "Duration Gap"}

A "duration de um "portifolio" de ativos ou de passivos é obtida das informações dos futuros fluxos de caixa e das taxas de juros do mercado. Idealmente, um banco pode procurar o "matching" entre seus "portifolios" de ativos e passivos, passando a controlar a exposição a que está sujeito seu patrimônio líquido. Quando as "durations" de seus ativos e passivos estão "matched", o movimento geral de taxas produzirá os mesmos efeitos nos valores presentes de ativos e passivos.

"Duration Gap" é a medida de "mismatch" das "durations" entre ativos e passivos que, teoricamente no mínimo, nos fornece um índice de esposição à taxa de juros do patrimônio líquido.

A expressão para "duration gap" (DG) é:

$D G: D_{A}-\left(\frac{P}{A}\right) D_{P}$

Onde:

$A=$ valor de mercado dos ativos

$\mathrm{P}=$ valor de mercado dos passivos

$\mathrm{D}_{\mathrm{A}}=$ "duration" dos ativos

$\mathrm{D}_{\mathrm{P}}=$ "duration" dos passivos

\section{4) Conclusões}

As principais conclusões que podem ser despreendidas deste artigo são:

- Os efeitos de risco de mudanças de taxas de juros têm sido mensurados pela aplicação dos conceitos de "gap" básico e "gap" periódico, que trazem em seu bojo muitas simplificações, principalmente quanto aos riscos escondidos dentro dos prazos sob análise. Assim,

Caderno de Estudos nº10, São Paulo, FIPECAFI, Maio/1994 
propusemos uma modificação na metodologia, no sentido de trabalharmos no "gap" formado pela diferença dos saldos médios em valor presente dos ativos e passivos. Dessa forma, transformamos as posições estáticas em posições dinâmicas e ilustramos com um exemplo para provar sua melhor precisão.

- Outra metodologia utilizada para cálculo dos efeitos de mudanças de taxas de juros é a "duration". Observamos e concluímos que a estimativa do valor de um ativo pelo prazo médio, por ser exponencial com o cálculo exato do valor presente, é mais precisa do que a calculada pela "duration" (linear) para variações pequenas de taxa. Entretanto, essa estimativa pode ser tornar menos precisa à medida que procuramos utilizar o método para oscilações maiores na taxa de juros. A metodologia do prazo médio, com foi aquí apresentada não tem sido. A metodologia do prazo médio, como foi aquí apresentada não tem sido contemplada na bibliografia internacional, nem em termos práticos pelos bancos. Provavelmente, pelo não uso rotineiro de juros exponenciais.

- Cabe frisar que a "duration" e o prazo médio são instrumentos eficazes para "hefging", pois possibilitam reduzir o efeito da mudança na taxa de juros na margem financeira. 